\title{
Vent Fauna on the Central Indian Ridge
}

\author{
Hiromi Watanabe and Girish Beedessee
}

\begin{abstract}
In deep-sea hydrothermal vent fields, faunal distribution is associated with the geochemical environments generated by hydrothermal vent activity. Hydrothermal vent fields on the Central Indian Ridge (CIR) are associated with vent fauna which is thought as a mixture of Atlantic and Pacific and are discretely distributed along the ridge axis of more than $1,000 \mathrm{~km}$ apart. In this chapter, faunal distribution in hydrothermal vent fields on the CIR is summarized at the intra- and inter-field levels. The species composition of the vent fauna in the four vent fields hitherto known is reviewed and updated, and faunal resemblance among the four vent fields of the CIR appears to reflect the number of species recorded, indicating that faunal surveys are not sufficient in describing the whole vent fauna on the CIR. All the genetic studies of the CIR vent fauna have indicated a high genetic connectivity among the local populations, despite the many potential dispersal barriers existing between the vent fields. On the basis of the spatial distribution of vent species in a vent field, typical vent fields on the CIR were classified into six zones, of which the central two zones are often covered by Rimicaris swarms in the Kairei and Edmond fields. The close relationship between vent fauna from the CIR and the western Pacific, compared to those from other regions, is highlighted. Knowledge of the Indian Ocean vent fauna is limited, and further quantitative information on the biodiversity of vent fauna will provide clues to the formation of biogeographical regions and the dispersal of vent fauna among deep-sea hydrothermal vent fields.
\end{abstract}

\section{Keywords}

Biodiversity $\bullet$ Biogeography $\bullet$ Faunal similarity $\bullet$ Indian Ocean $\bullet$ Zonation

The online version of this chapter (doi:10.1007/978-4-431-54865-2_16) contains supplementary material, which is available to authorized users.

H. Watanabe $(\bowtie)$

Department of Marine Biodiversity Research, Japan Agency for Marine-Earth Science and Technology, Kanagawa 237-0061, Japan e-mail: hwatanabe@jamstec.go.jp

G. Beedessee

Mauritius Oceanography Institute, France Centre, Victoria Avenue, Quatre-Bornes, Mauritius

Department of Chemistry and Biomolecular Sciences, Macquarie University, Sydney, NSW 2109, Australia

\subsection{Background}

The Indian Ocean has three spreading ridge branches, the Central Indian Ridge (CIR; see Okino et al. Chap. 11), the Southwest Indian Ridge (SWIR), and the Southeast Indian Ridge (SEIR). Their spreading rates vary from the ultraslow spreading of the SWIR ( $\leq 12 \mathrm{~mm} / \mathrm{year})$ to the intermediate spreading of the SEIR and CIR (50-60 mm/year) (DeMets et al. 1990; Snow and Edmonds 2007). The biology of CIR hydrothermal vents remains little known, because of inaccessibility. An important physical link between the MidAtlantic Ridge (MAR) hydrothermal vents and the western Pacific arc and backarc basins, the CIR hydrothermal vents 
consist of a blend of Atlantic and Pacific faunas (Van Dover et al. 2001; Nakamura et al. 2012). Since the discovery of a deep-sea hydrothermal vent field and associated fauna in the Indian Ocean in 2000 at the Kairei vent field near the Rodriguez Triple Junction (RTJ) (Hashimoto et al. 2001), our knowledge of the biogeography of vent fauna at the global level has been improved. Subsequent to the discovery of the Kairei field, three other vent fields were discovered on the CIR; Edmond field by (Van Dover et al. 2001) and DoDo and Solitaire fields by Nakamura et al. (2012). Recently, a hydrothermal vent was discovered on the SWIR (Tao et al. 2012). On the SEIR, hydrothermal plumes have been observed, but vent activity has yet to be observed (Scheirer et al. 1998).

In this chapter, we review the previous studies undertaken on the CIR, provide new insights based on our recent findings, and discuss faunal distributions and its biogeographical relationships.

\subsection{Distribution and Connectivity of Vent Fauna}

Vent fauna associated with the CIR from the Kairei field has been independently described by Hashimoto et al. (2001) and Van Dover et al. (2001); the latter with a discovery of vent fauna in the Edmond field. Recently, vent fauna was also reported in the Solitaire and DoDo vent fields (Nakamura et al. 2012). Here, we review the original faunal list and provide an updated faunal list of the four vent fields on the CIR (Table 16.1). As described in detail in the later sections of this chapter, the faunal composition of the CIR shows a similarity to the central and southern parts of the Pacific vent fauna, whereas some vent species are endemic to the Indian Ocean. As generally known, sampling effort have made significant effects on the accurate description of the biodiversity (Magurran 2004). Because of the inaccessibility of the Indian Ocean vent fields, the vent fauna is not yet fully described. The biodiversity of the Indian Ocean vent may be underestimated and it causes specificity of vent fauna in the Indian Ocean. In this section, previous reports are reviewed for the three major taxa (Annelida, Arthropoda, and Mollusca), with recent results from TAIGA project.

Annelida. In total, 12 species have been reported in the CIR hydrothermal vent fields, and five genera have been regarded as endemic to this region (Van Dover et al. 2001). No tubeworms have been found in the Indian Ocean vent fields. The absence of alvinellid polychaetes has been regarded as one of the characteristics of Indian Ocean vent fauna; however, in recent investigations, several colonies of alvinellid polychaetes were observed in the Solitaire vent field (Nakamura et al. 2012) as well as in the Edmond field. The genus and species of these alvinellids are still under investigation, and the results will provide a clue to understanding worldwide faunal relationships in deep-sea hydrothermal vent fields.

Archinome jasoni is a recently described polychaete, and it is distributed in the hydrothermal vent fields in the southwestern Pacific, Atlantic, and Indian Oceans (Borda et al. 2013). Phylogenetic analyses of mitochondrial DNA have revealed that the $A$. jasoni on the CIR is more closely related to the A.jasoni in the Atlantic vent field than to the A.jasoni in the southwestern Pacific vent fields (Borda et al. 2013).

The identification of polychaete species in the Solitaire field is still in progress, and the relationship between the Solitaire and Kairei fields is not yet fully understood. A detailed investigation of the annelid composition of the CIR is required.

Arthropoda. In total, six species have been reported in the CIR hydrothermal vent fields, and they are all appear to be endemic to this region, but the genera are all shared with Pacific and Atlantic vent fauna (Van Dover et al. 2001).

Rimicaris kairei is the most abundant animal in the known vent fields of the Indian Ocean, both on the CIR, and on the SWIR (Nakamura et al. 2012; Tao et al. 2012). No genetic differentiation exists between $R$. kairei populations in the Kairei and Edmond fields (Van Dover et al. 2001). Recently, population genetic analysis of $R$. kairei was undertaken using a partial mitochondrial cytochrome oxidase $c$ subunit I (COI) sequence, of the three vent populations on the CIR; again, no genetic differences were detected (Beedessee et al. 2013). The congeneric species $R$. exoculata and $R$. hybisae are found on both the MAR and the Mid-Cayman Rise (MCR) (Nye et al. 2012). The distribution of the Rimicaris shrimp may reflect the historical connectivity between these three regions.

Mirocaris indica is the second most abundant crustacean in the CIR vent fields, after $R$. kairei. However, it may sometimes be misidentified as "Chorocaris" (Komai et al. 2006); indeed, Hashimoto et al. (2001), Van Dover et al. (2001), and Nakamura et al. (2012) have described it as "Chorocaris." Although most Chorocaris shrimps are found in the Pacific Ocean, the solitary congeneric species M. fortunata is found only on the MAR (Komai and Segonzac 2003). The presence of the Mirocaris shrimp on the CIR supports the hypothesized relationship between the vent fauna on the MAR and that on the CIR.

The bythograeid crab Austinograea rodriguezensis is a common species found in all four-vent sites of the CIR (Tsuchida and Hashimoto 2002; Nakamura et al. 2012). Its distribution varies from location to location, although it is most abundant in the Kairei and Solitaire fields, and least abundant in the DoDo field. No significant differences were detected in genetic diversity between the Solitaire and Kairei populations (Beedessee et al. 2013), which is consistent with the results of a previous study that found a $0.2 \%$ difference in genetic 
Table 16.1 Species list of vent fauna in the Central Indian Ridge (Updated from Van Dover et al. (2001) and Nakamura et al. (2012))

\begin{tabular}{|c|c|c|c|c|c|c|}
\hline Phylum & Family & Species & Dodo & Solitaire*1 & Kairei & Edmond*2 \\
\hline Cnidaria & Actinostolidae & Marianactis sp. & + & + & + & + \\
\hline \multirow[t]{6}{*}{ Arthropoda } & Bythograeidae & A. rodriguezensis & + & + & + & + \\
\hline & Alvinocarididae & Rimicaris kairei & + & + & + & + \\
\hline & & Mirocaris indica & & + & + & + \\
\hline & Galatheidae & Munidopsis sp. & & + & + & \\
\hline & Neolepadidae & Neolepadidae gen et sp. & & + & + & \\
\hline & Chionelasmatidae & Eochionelasmus sp. & & + & + & \\
\hline \multirow[t]{14}{*}{ Mollusca } & Mitilidae & Bathymodiolus marisindicus & & + & + & \\
\hline & Lepetodridae & Lepetodrilus sp. & & + & + & \\
\hline & & Pseudorimula sp. & & & + & \\
\hline & Neolepetopsidae & Eulepetopsis sp. & & + & + & \\
\hline & Peltospiridae & Scaly-foot gastropod & & + & + & \\
\hline & Phenacolepadidae & Shinkailepas sp. & & + & + & \\
\hline & Provannidae & Alviniconcha sp. type 3 & & + & + & + \\
\hline & & Desbruyeresia sp. & & + & + & \\
\hline & Skeneidae & Bruceiella sp. & & & + & \\
\hline & Turridae & Phymorhynchus sp. & & + & + & + \\
\hline & Simrothiellidae & Helicoradomenia? sp. & & & + & \\
\hline & Sutilizonidae & Sutilizona sp. & & & + & \\
\hline & - & Slit limpet sp. 1 & & & + & \\
\hline & - & Slit limpet sp. 2 & & & + & \\
\hline \multirow[t]{12}{*}{ Annelida } & Alvinellidae & Alvinellid gen et sp. & & + & & + \\
\hline & Ampharetidae & Amphisamytha sp. & & & + & \\
\hline & Amphinomidae & Archinome jasoni & & + & + & \\
\hline & Capitellidae & Capitellid sp. 1 & & & + & \\
\hline & Dorvilleidae & Ophyotrocha sp. & & & + & \\
\hline & Hesionidae & Hesionoid sp. 1 & & & + & \\
\hline & & Hesionid sp. 2 & & & + & \\
\hline & Polynoidae & Branchinotogluma sp. & & + & + & + \\
\hline & & Branchipolynoe sp. & & & + & \\
\hline & & Harmothoe? sp. & & & + & \\
\hline & & Levensteiniella? sp. & & & + & \\
\hline & Spionidae & Prionospio sp. & & & + & \\
\hline Echinodermada & - & Apodacean gen et sp. & & + & & \\
\hline Chordata & Macroudidae & Macrourid gen et sp. & & + & & \\
\hline Nemertea & - & Unidentified & & + & + & \\
\hline Platyhelminthes & - & Unidentified & & + & + & \\
\hline Number of taxaon & & 37 & 3 & 22 & 34 & 6 \\
\hline
\end{tabular}

*1: without identification of polychates, $* 2$ : compiled from Van Dover et al. (2001), +: presence

diversity between Austinograea populations in the Kairei and Edmond fields (Van Dover et al. 2001). Congeneric species are found in the western Pacific vent fields, whereas crabs of different genera are found in the eastern Pacific and MAR vent fields (summarized in Desbruyères et al. 2006).

Other crustaceans are found on the periphery of the vent fields of the CIR. Galatheid crabs of the genus Munidopsis are an important component of the macrofauna of the Kairei and Solitaire fields, with $M$. laticorpus being the species found in the Kairei field (Cubelio et al. 2008). Munidopsis crabs in the Solitaire field inhabit areas distant from venting chimneys, most likely to avoid predation. Munidopsis crabs are distributed globally on the deep-sea floor, not only in vent fields, but also in non-vent environments. Barnacles of the family Neolepadidae and Chionelasmatidae are shown to aggregate in patches at the periphery of the vent fields. The species identification of these barnacles is under investigation, but the congeneric species are all found on the western and eastern parts of the southern Pacific.

Mollusca. In total, 14 species have been reported in the CIR hydrothermal vent fields. Only the scaly-foot gastropod is regarded as an endemic taxon to this region, probably at the genus level, and it is one of the representative animals of 
the Indian Ocean vent fauna, both on the CIR and SWIR (Van Dover et al. 2001; Tao et al. 2012). The scaly-foot gastropod was first reported from the Kairei field, and is considered unique because of its iron-coated sclerites (Warén et al. 2003), and the presence of bacterial symbionts in its esophageal gland (Goffredi et al. 2004). Analysis of its population genetics revealed no genetic differences between the scaly-foot populations in the Kairei and Solitaire fields (Nakamura et al. 2012). The symbiotic bacteria of the scalyfoot gastropod, as well as those of Alviniconcha gastropods, are summarized with environmental microbial communities in Chap. 12 (Nakamura and Takai).

The genus Alviniconcha was first discovered in the Alice Spring vent field of the Mariana Trough, with the only species described to date being $A$. hessleri. The large, hairy Alviniconcha snails, which also host bacterial symbionts, are dominant in the vent fields of the Mariana Trough, and in the southernmost vent fields of the western Pacific region, but are less abundant in the Indian Ocean. Several lineages of these gastropods have been detected using molecular approaches (Kojima et al. 2001; Beinart et al. 2012). However, the taxonomic description of this species is still in progress, and only provisional names are used. The population differentiation of this gastropod in the CIR was first examined using a partial sequence of the mitochondrial 16SrRNA gene with no genetic differentiation between the Kairei and Edmond fields (Van Dover et al. 2001), whereas recent investigations have revealed significant genetic differentiation between the local populations in the Edmond and Solitaire fields (Beedessee et al. 2013). Phymorhynchus, a globally distributed gastropod genus that inhabits the periphery of vent field, appears to be omnivorous species, as its nitrogen isotopic signature was not high compared to that of other animals without symbionts (Van Dover 2002).

Some gastropods, listed by Hashimoto et al. (2001), have been updated after recent investigation and sample re-examinations. A cancellariid gastropod is now described as Iphinopsis boucheti, and a Provanna gastropod was re-classified in the related genus Desbruyeresia (Okutani et al. 2004). Bathyacmaea sp. was probably a misidentification of Eulepetopsis, or another limpet (Bathyacmaea was listed by Hashimoto et al. (2001) as a collected sample, but only Lepetodrilus and Eulepetopsis were listed in the database of JAMSTEC biological samples, as well as being in sample storage).

Bathymodiolus marisindicus is a large bivalve with symbiotic bacteria, and is described as an endemic species to the CIR vent fields. However, the previous genetic analysis, based on a partial sequence of the mitochondrial NADH dehydrogenase 4 (ND4) gene, revealed that $B$. marisindicus shared a haplotype with the congeneric $B$. brevior in the North Fiji Basin and with B. septemdierum in the Myojin Knoll (Kyuno et al. 2009). The sequence of the ND4 gene is widely used in population genetic analyses as it is contains sufficient information to perform such analyses (Kyuno et al. 2009), therefore, the results of Kyuno et al. (2009) raise the possibility that these three species may be geographic variations of a single species, that has a high dispersal ability.

Other Phyla. A conspicuous red flatworm (probably, a platyhelminth) was observed in the Kairei and Solitaire fields (Van Dover et al. 2001; Nakamura et al. 2012). The occurrence of this animal in the vent fields is unique to the CIR vents, whereas red nemertean worms have been found in the eastern Pacific vent fields (Rogers et al. 1996). An apodacean holothurian was observed in the Kairei and Solitaire fields on the CIR; that in the Kairei field was assigned to the family Synaptidae (Hashimoto et al. 2001). The holothurian Chiridota hydrothermica has been found in the Manus Basin hydrothermal vent field, together with large gastropods of the genera Alviniconcha and Ifremeria, and barnacles (Smirnov et al. 2000). C. hydrothermica was also found in both the eastern and western sides of the southern Pacific Ocean, with associated fauna that included mussel clumps (Smirnov et al. 2000). The density of $C$. hydrothermica was significantly affected by lava type (Podowski et al. 2010). Although their geographical distribution has not yet been comprehensively investigated, holothurians may be among the most common animals inhabiting the periphery of hydrothermal vent fields. The sea anemone Marianactis was observed consuming R. kairei, and this observation was supported by its stable isotopic signature (Van Dover 2002).

\subsection{Zonation in a Vent Field}

Vent fauna show variation along steep environmental gradients, or patchiness, which is referred to "zonation". In the CIR, two types of vent areas have been recognized; the chimney-rich Kairei and Edmond fields, and the diffuse flow-rich Solitaire field. $R$. kairei swarms near vents are abundant in the chimney-rich vent fields, but are patchily distributed in the diffuse flow-rich vent field. The fauna on the chimney surface, such as the scaly-foot gastropod and the alvinellid polychaetes, are therefore covered by shrimp swarms in the chimney-rich vent fields, but are exposed in the diffuse flow-rich vent field. Therefore, we will describe the zonation in the diffuse flow-rich vent field first, followed by some remarks in the chimney-rich vent fields later.

In the diffuse flow-rich Solitaire field, faunal assemblages are distributed in the following zones: Zone 1, an alvinellid aggregation; Zone 2, a scaly-foot and Alviniconcha gastropod-hosted community; Zone 3, a Bathymodiolushosted community; Zone 4, a peripheral Phymorhynchus and Marianactis community; Zone 5, a peripheral barnacle-dominated community; and Zone 6, a mobile Rimicaris aggregation (Fig. 16.1). Alvinellid aggregations are commonly found in the high temperature zone of 
Fig. 16.1 Nonmetric

multidimensional scaling

(nMDS) plot of faunal similarities

among the four vent fields of the

Central Indian Ridge based on

Table 16.1

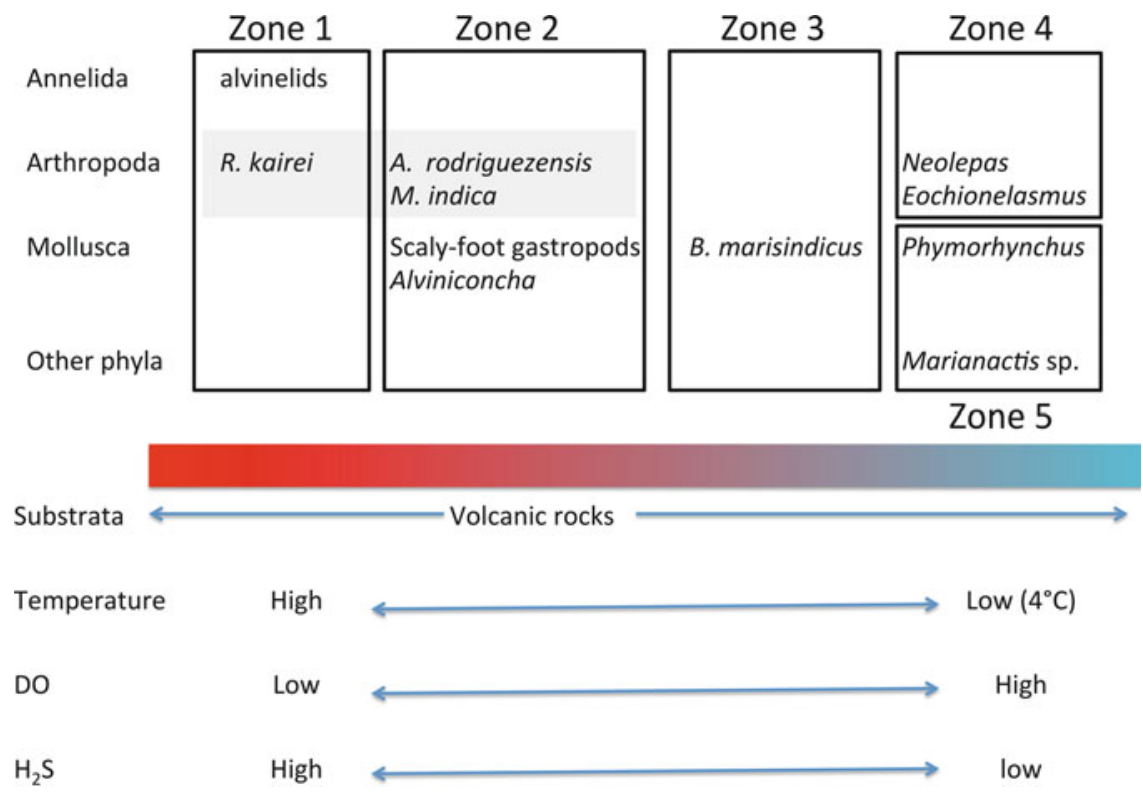

hydrothermal vent fields, in both the western and eastern Pacific, but are not abundant on the CIR. Mobile species, such as $R$. kairei, may cover such aggregations in the chimney-rich vent fields. Both scaly-foot and Alviniconcha gastropods harbor symbiotic bacteria (Stein et al. 1988; Goffredi et al. 2004), but their distributions are slightly different; scaly-foot gastropods inhabit the diffuse-flow transitional zone, whereas Alviniconcha inhabits more gentle environments. Bathymodiolus-hosted communities are usually found outside Rimicaris aggregations, and are easily observed, even in the chimney-rich vent fields. As for the mobile fauna, $R$. kairei does not only aggregate at the high temperature vents, but also scattered in the diffuse-flow area, in a similar manner as $M$. indica and A. rodriguezensis. In $R$. kairei and $A$. rodriguezensis, carapace size, and stable isotopic ratio, are correlated (Van Dover 2002), suggesting that the feeding ecologies of these animals vary according to their growth stage; or that their habitats may be changing.

Some special features of the zonation in the Kairei field are noteworthy. Shed Rimicaris molts accumulate at the base of the Monju chimney, just below the Rimicaris aggregation. Archinome polychaetes are abundant in this area, and its isotope signatures indicates that these polychaetes consumes the Rimicaris molts (Van Dover 2002). Flatworm aggregations are also a feature of this region, whereas no such aggregations have been observed in the Solitaire field.

\subsection{Inter-Field similarity}

To investigate the overall similarity between the vent fauna on the CIR, Jaccard's index of similarity $\left(C_{J}\right)$ was calculated based on the species occurrence data (Table 16.1), and the

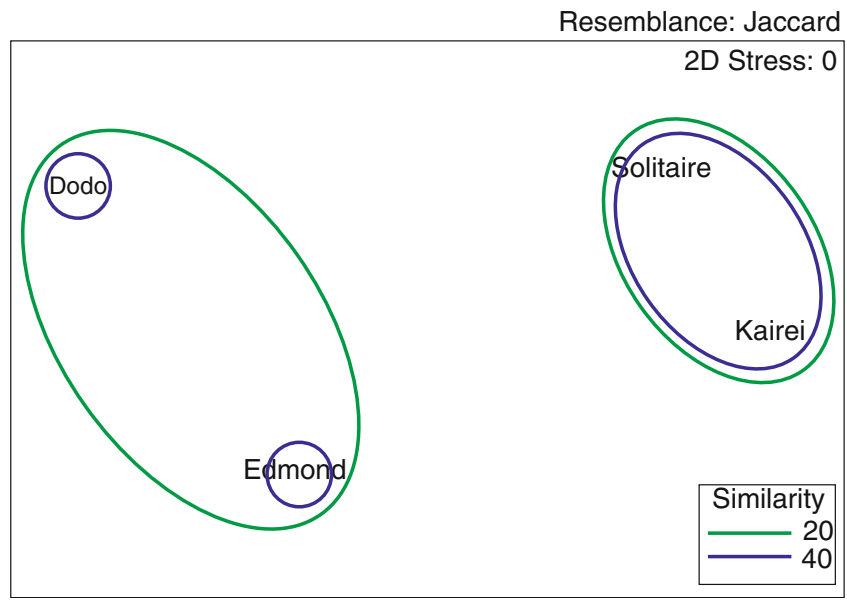

Fig. 16.2 Summary of the zonation of vent fauna on the Central Indian Ridge

result was visualized using nonmetric multidimensional scaling (nMDS; Fig. 16.2). Faunal similarity among the four vent fields was less than $50 \%$; the vent fauna in the Solitaire and Kairei fields were the most similar, despite their geographical locations. However, these results were driven entirely by differences in the number of species observed in each vent field. In total, 42 species were reported on the CIR; 40 and 22 species were reported in the Kairei and Solitaire fields, respectively, but only six and three species were reported in the Edmond and DoDo fields, respectively (Table 16.1). The number of species is generally correlated with the number of investigations carried out and it seemed to be consistent with the result shown as Fig. 16.2. On the other hand, activities of hydrothermal vents were also clearly different between the Edmond and DoDo fields, i.e., active chimneys with flourish vent fauna were observed in the Edmond field but only scattered vent faunas were observed in the DoDo 
field (Nakamura et al. 2012). To be accurate, comparative investigation in the Edmond field is required.

\subsection{Faunal Similarities with Other Biogeographical Regions}

The biogeography of the Indian Ocean vent fauna was first discussed when the second CIR vent field, the Edmond vent field, was discovered (Van Dover et al. 2001). However, knowledge of the vent fauna in the Kairei and Edmond fields was limited and specificity of vent fauna in the Indian Ocean is still under discussion (Bachraty et al. 2009; Rogers et al. 2012). The present review updates the previous dataset, along with those shown in Kojima and Watanabe (Chap. 25) and Watanabe and Kojima (Chap. 34). Similarity among global vent fields at the genus level is shown by the nMDS plot (Fig. 16.3), based on $C_{J}$ calculated using the species occurrence data in Suppl. 16.1. The results show that the closer relationships of the CIR fauna to the Pacific vent faunas, particularly to those in the Mariana Trough $\left(C_{J}=31.579\right)$ and the Manus Basin $\left(C_{J}=26.667\right)$, than to the Atlantic vent faunas.

Recent discoveries, such as the distribution of alvinellids and holothurians, and the close genetic relationship between B. marisindicus and its congeneric relatives in the western Pacific, B. brevior and B. septemdierum, also indicate that the CIR vent fauna shares a closer relationship with the vent faunas of the western Pacific. On the other hand, an Archinome polychaete is found on the CIR, the MAR, and in the western Pacific vent fields, and the A. jasoni on the CIR is genetically closer to the A. jasoni on the MAR than to the A. jasoni found in the Pacific Ocean (Borda et al. 2013). There must be complicated history of biogeography. However, the present results support the hypothesis that the Indian Ocean ridge systems act as a corridor for contemporaneous dispersal between ocean basins (German et al. 1998; Van Dover 2002).

In addition to the CIR, two other ocean ridge systems are found in the Indian Ocean: the SWIR and SEIR. The SWIR is particularly interesting, as it is an ultraslow-spreading ridge system that should act as a corridor for vent faunal gene flow between the Atlantic and Pacific vent fields (German et al. 1998). The recent discovery of a vent field on the SWIR will provide new insights into the biogeography of the Indian Ocean (e.g., the distribution of scaly-foot gastropods on the SWIR (Tao et al. 2012)). On the other hand, the present results suggest that SEIR may not act as a corridor to the Pacific Ocean, as most of the southwestern Pacific vent fauna showed relatively low similarity to the CIR vent fauna, while relatively high similarity was observed between the CIR and the equatorial western Pacific vent faunas. The historical seafloor spreading (Heirtzler et al. 1968) or Indonesian Throughflow (Gordon and Fine 1996) may be among the important factors influencing faunal connectivity between the CIR and western Pacific vent fields.

\subsection{Conclusion}

More than 10 years of study have provided basic information on the fauna associated with the CIR vent fields, including intra- and inter-field variations. This chapter has described zonation of vent fauna in the CIR vent fields and inter-field similarity of vent fauna. Furthermore, a similarity analysis of global vent fauna suggested close relationships between the CIR and western Pacific vent faunas at the genus level. The CIR vent fields contain a mixture of Atlantic and Pacific vent fauna, although the CIR itself is not connected to any other ridge systems, unlike the SWIR, which is connected to the MAR, or the SEIR, which is
Fig. 16.3 Nonmetric multidimensional scaling (nMDS) plot of faunal similarities among global vent fields based on Suppl. 16.1

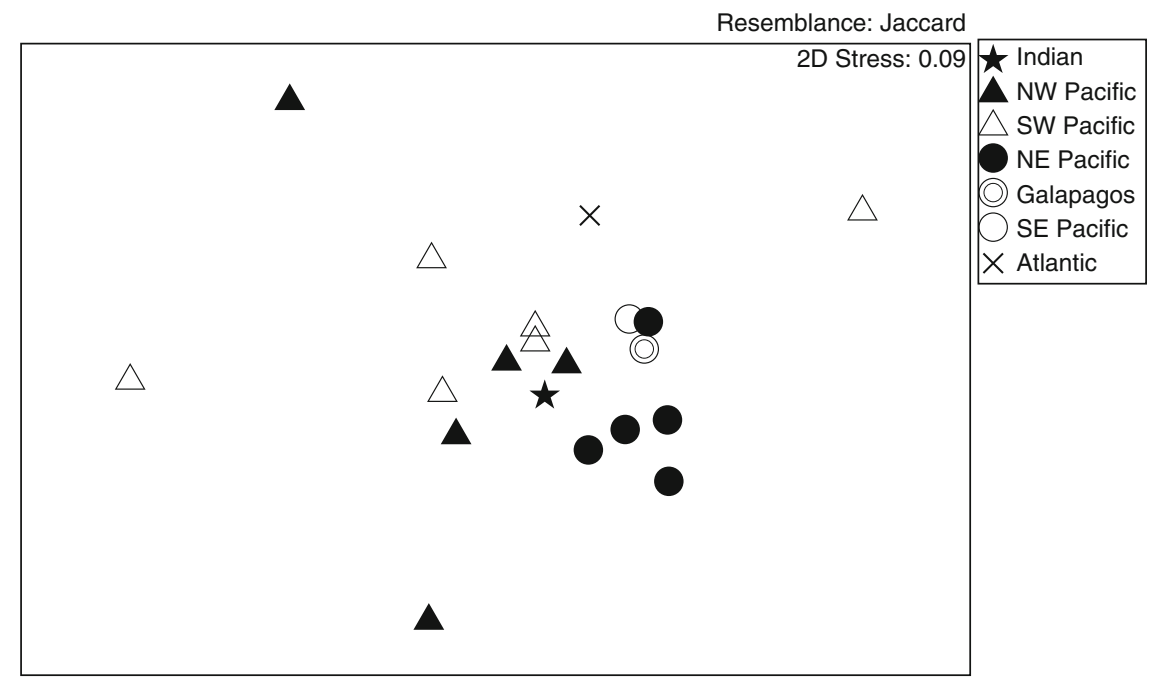


connected to the Pacific-Antarctic Ridge. In addition, the spreading rates of the three ridge systems in the Indian Ocean are different. Therefore, elucidating the biogeography of the three ridge systems in the Indian Ocean is important for understanding the global biogeography of vent fauna, not only for the accumulation of information regarding vent fauna distributions but also for elucidating the mechanisms of faunal dispersal and generation of biogeographical regions among vent fields.

Acknowledgments We are grateful to the on-board scientists of the YK09-13 and YK13-02 cruises of the R/V Yokosuka and HOV Shinkai6500, and Drs. Satoshi Mitarai and Dhugal Lindsay for discussion of oceanographic states. This study was supported by the "TAIGA project," which was funded by a Grant-in-Aid for Scientific Research on Innovative Areas (No. 20109001, 20109004, 20109005) from the Ministry of Education, Culture, Sports, Science and Technology (MEXT), Japan, and Canon Foundation.

Open Access This chapter is distributed under the terms of the Creative Commons Attribution Noncommercial License, which permits any noncommercial use, distribution, and reproduction in any medium, provided the original author(s) and source are credited.

\section{References}

Bachraty C, Legendre P, Desbruyéres D (2009) Biogeographic relationships among deep-sea hydrothermal vent faunas at global scale. Deep Sea Res I 56:1371-1378

Beedessee G, Watanabe H, Ogura T, Nemoto S, Yahagi T, Nakagawa S, Nakamura K, Takai K, Koonjul M, Marie DEP (2013) High connectivity of animal populations in deep-sea hydrothermal vent fields in the Central Indian Ridge relevant to its geological setting. PLoS One 8:e81570

Beinart RA, Sanders JG, Faure B, Sylva SP, Lee RW, Becker EL, Gartman A, Luther GW III, Seewald JS, Fisher CR, Girgius PR (2012) Evidence for the role of endosymbionts in regional-scale habitat partitioning by hydrothermal vent symbioses. Proc Natl Acad Sci USA 109:E3241-E3250

Borda E, Kudenov JD, Chevaldonné P, Blake AJ, Desbruyères D, Fabri MC, Hourdez S, Pleijel F, Shank TM, Wilson NG, Schulze A, Rouse GW (2013) Cryptic species of Archinome (Annelida: Amphinomida) from vents and seeps. Proc R Soc B 280:20131876. doi:10.1098/rspb.2013.1876

Cubelio S, Tsuchida S, Watanabe S (2008) New species of Munidopsis (Decapoda: Anomura: Galatheidae) from hydrothermal vent areas of Indian and Pacific Oceans. J Mar Biol Ass U K 88:111-117

DeMets C, Gordon RG, Argus DF, Stein S (1990) Current plate motions. Geophys J Int 101:425-478

Desbruyères D, Segonzac M, Bright $M$ (eds) (2006) Handbook of deepsea hydrothermal vent fauna. Second completely revised edition. Denisia 18:544

German CR, Baker ET, Mevel C, Tamaki K, the FUJI Science Team (1998) Hydrothermal activity along the southwest Indian ridge. Nature 395:490-493

Goffredi SK, Warén A, Orphan VJ, Van Dover CL, Vrijenhoek RC (2004) Novel form of structural integration between microbes and a hydrothermal vent gastropod from the Indian Ocean. App Environ Microbiol 70:3082-3090

Gordon AL, Fine RA (1996) Pathways of water between the Pacific and Indian oceans in the Indonesian seas. Nature 379:146-149
Hashimoto J, Ohta S, Gamo T, Chiba H, Yamaguchi T, Tsuchida S, Okudaira T, Watabe H, Yamanaka T, Kitazawa M (2001) First hydrothermal vent communities from the Indian Ocean discovered. Zool Sci 18:717-721

Heirtzler JR, Dickson GO, Herron EM, Pitman WC III, Le Pichon X (1968) The magnetic anomalies, geomagnetic field reversals and motions of the ocean floor and continents. J Geophys Res 73:2119-2136

Kojima S, Segawa R, Fijiwara Y, Fujikura K, Ohta S, Hashimoto J (2001) Phylogeny of hydrothermal-vent-endemic gastropods Alviniconcha spp. from the western Pacific revealed by mitochondrial DNA sequences. Biol Bull 200:298-304

Komai T, Segonzac M (2003) Review of the hydrothermal vent shrimp genus Mirocaris, redescription of $M$. fortunata and reassessment of the taxonomic status of the family Alvinocarididae (Crustacea: Decapoda: Caridea). Cah Biol Mar 44:199-215

Komai T, Martin JW, Zala K, Tsuchida S, Hashimoto J (2006) New species of Mirocaris (Crustacea: Decapoda: Caridea: Alvinocarididae) associated with hydrothermal vents on the Central Indian Ridge, Indian Ocean. Sci Mar 70:109-119

Kyuno A, Shintaku M, Fujita Y, Matsumoto H, Utsumi M, Watanabe H, Fujiwara Y, Miyazaki J (2009) Dispersal and differentiation of deep-sea mussels of the genus Bathymodiolus (Mytilidae, Bathymodiolinae). J Mar Biol. doi:10.1155/2009/625672

Magurran AE (2004) Measuring biological diversity. Blackwell, Massachusetts, Oxford, Victoria, $256 \mathrm{pp}$

Nakamura K, Watanabe H, Miyazaki J, Takai K, Kawagucci S, Noguchi T, Nemoto S, Watsuji T, Matsuzaki T, Shibuya T, Okamura K, Mochizuki M, Orihashi Y, Ura T, Asada A, Daniel M, Koonjul M, Singh M, Beedessee G, Bhikajee M, Tamaki K (2012) Discovery of new hydrothermal activity and chemosynthetic fauna on the Central Indian Ridge at $18-20^{\circ}$ S. PLoS One 7:e32965

Nye V, Copley J, Plouviez S (2012) A new species of Rimicaris (Crustacea: Decapoda: Caridea: Alvinocarididae) from hydrothermal vent fields on the Mid-Cayman Spreading Centre Caribbean. J Mar Biol Ass UK 92:1057-1072

Okutani T, Hashimoto J, Sasaki T (2004) New gastropod taxa from a hydrothermal vent (Kairei field) in the central Indian Ocean. Venus 63:1-11

Podowski EL, Ma S, Luther GW III, Wardrop D, Fisher CR (2010) Biotic and abiotic factors affecting distributions of megafauna in diffuse flow on andesite and basalt along the Eastern Lau Spreading Center. Tonga Mar Ecol Prog Ser 418:25-45

Rogers AD, Gibson R, Tunnicliffe V (1996) A new genus and species of monostiliferous hoplonemertean colonizing an inchoate hydrothermal. Field on Juan de Fuca Ridge. Deep-Sea Res I 43:1581-1599

Rogers AD, Tyler PA, Connelly DP, Copley JT, James R, Larter RD, Linse K, Mills RA, Garabato AN, Pancost RD, Pearce DA, Polunin NVC, German CR, Shank T, Boersch-Supan PH, Alker BJ, Aquilina A, Bennett SA, Clarke A, Dinley RJJ, Graham AGC, Green DRH, Hawkes JA, Hepburn L, Hilario A, Huvenne VAI, Marsh L, Ramirez-Llodra E, Reid WDK, Roterman CN, Sweeting CJ, Thatje S, Zwirglmaier K (2012) The discovery of new deep-sea hydrothermal vent communities in the Southern Ocean and implications for biogeography. PLoS Biol 10:e1001234

Scheirer DS, Baker ET, Johnson KTM (1998) Detection of hydrothermal plumes along the Southeast Indian Ridge near the AmsterdamSt. Paul Plateau. Geophys Res Lett 1998(25):97-100

Smirnov AV, Gebruk AV, Galkin SV, Shank T (2000) New species of holothurian (Echinodermata: Holothuroidea) from hydrothermal vent habitats. J Mar Biol Ass UK 80:321-328

Snow JE, Edmonds HN (2007) Ultraslow-spreading ridges: rapid paradigm changes. Oceanography 20:90-101

Stein JL, Cary C, Hessler RR, Ohta S, Vetter RD, Childress JJ, Felbeck $\mathrm{H}$ (1988) Chemoautotrophic symbiosis in a hydrothermal vent gastropod. Biol Bull 174:373-378

Tao C, Lin J, Guo S, Chen YJ, Wu G, Han X, German CR, Yoerger DR, Zhou N, Li H, Su X, Zhu J, the DY115-19 (Leg 1) and DY115-20 
(Legs 4-7) Science Parties (2012) First active hydrothermal vents on an ultraslow-spreading center: Southwest Indian Ridge. Geology 40:47-50

Tsuchida S, Hashimoto J (2002) A new species of bythograeid crab, Austinograea rodriguezensis (Decapoda, Brachyura), associated with active hydrothermal vents from the Indian Ocean. J Crust Biol 22:642-650

Van Dover CL (2002) Trophic relationships among invertebrates at the Kairei hydrothermal vent field (Central Indian Ridge). Mar Biol 141:761-772
Van Dover CL, Humphris SE, Fornari D, Cavanaugh CM, Collier R, Goffredi SK, Hashimoto J, Lilley MD, Reysenbach AL, Shank TM, Von Damm KL, Banta A, Gallant RM, Götz D, Green D, Hall J, Harmer TL, Hurtado LA, Johnson P, McKiness ZP, Meredith C, Olsen E, Pan IL, Turnipseed M, Won Y, Young CR III, Verijenhoek RC (2001) Biogeography and ecological setting of Indian Ocean hydrothermal vents. Science 294:818-823

Warén A, Bengtson S, Goffredi SK, Van Dover CL (2003) A hot-vent gastropod with iron-sulfide dermal sclerites. Science 302:1007 